\title{
PROMOVENDO REFLEXÕES SOBRE EDUCAÇÃO AMBIENTAL NO ENSINO DE QUÍMICA
}

\author{
Rafaela Engers Günzel1; Rosangela Inês Matos Uhmann²; Fabiane de Andrade Leite ${ }^{3}$
}

\section{RESUMO}

A necessidade de construirmos uma sociedade sustentável possui a escola que pode se constituir na principal aliada. Um dos desafios para formar cidadãos críticos e atuantes ecologicamente, tem na prática pedagógica do professor o modo de relacionar os conceitos científicos com as questões ambientais. Para tanto, apresentamos duas atividades desenvolvidas no estágio de docência em Química com alunos do $1^{\circ}$ ano do Ensino Médio. Momento em que a discussão ambiental foi levada para as aulas por meio de um questionário para desenvolver o pensamento acerca da temática. Concluímos elencando com necessidade da problematização das questões ambientais, pois os alunos possuem informações que precisam da mediação do professor para a elaboração do conhecimento, quando se almeja a relação conceitual e ambiental de forma intrínseca e sistemática.

Palavras-chave: Alimentação; Ensino de Química; Alfabetização Científica.

\section{PROMOTING REFLECTIONS ON ENVIRONMENTAL EDUCATION IN CHEMISTRY TEACHING}

\section{ABSTRACT}

The emerging need to build a sustainable society has the school that can be the main ally. One of the challenges to educate critically and ecologically active citizens has in the role of the teacher through his pedagogical practice how to relate scientific concepts to environmental issues. Therefore, the present work constitutes the presentation of two activities developed in the teaching stage in the discipline of Chemistry with students of the 1st year of High School. Moment at which the environmental discussion was taken to Chemistry classes through a questionnaire that intended to develop students' thinking about the subject. We conclude our study by stating with necessity the introduction of the problematization of environmental issues, since the students have a lot of

1 Graduada em Química Licenciatura pela Universidade Federal da Fronteira Sul (UFFS). Mestranda em Ensino de Ciências. Universidade Federal de Rio Grande (FURG). E-mail: rafaela.gunzel@gmail.com.

2 Doutora em Educação nas Ciências pela Unijuí. Professora do Curso de Química Licenciatura da UFFS, Campus Cerro Largo. E-mail: rosangela.uhmann@uffs.edu.br.

3 Doutora em Educação nas Ciências pela Universidade Regional do Noroeste do Estado do Rio Grande do Sul (Unijuí). Professora do Curso de Química Licenciatura da UFFS, Campus Cerro Largo. E-mail: fabianeleite@hotmail.com. 
information that requires the teacher's mediation for the elaboration of knowledge, especially when the conceptual and environmental relationship is sought in an intrinsic and systematic way.

Keywords: Feeding; Chemistry teaching; Scientific Literacy.

\section{Considerações Iniciais da Vivência Docente}

Muitos desafios nos envolvem durante nossa trajetória acadêmica no decorrer da formação inicial de professor. Um deles, o ensino e aprendizagem dos nossos alunos, se faz constante, ao (re)fazer, (re)pensar e (re)construir nossa prática pedagógica. A busca por uma educação com qualidade movimenta a formação inicial na procura de um ensino que propicie ao aluno ser um sujeito ativo no seu processo de aprendizagem, que se constitua como cidadão crítico e atuante socialmente.

Para o presente estudo, envolvemos a relação teoria e prática vivenciada no estágio de docência intrínseco no contexto escolar. Quando adentramos na sala de aula, enquanto professores, sabemos muito pouco sobre os alunos, não sabemos quem são ou o que esperam da escola, como aprendem e como podem vir a ter prazer na aprendizagem que vamos dialogar neste espaço (DELIZOICOV; ANGOTTI e PERNAMBUCO, 2002). Assim, partimos do pressuposto que os alunos são sujeitos epistêmicos e ontológicos, ou seja, tem capacidade de apropriar-se de conhecimentos ao interagir com diversos domínios e, portanto, não podem ser tratados como 'tábula rasa', pois interagem dialogicamente na construção do conhecimento escolar.

Nesse sentido, por meio do diálogo e da mediação, o professor junto aos alunos, contribui na construção de novos conhecimentos, agregados aos já existentes que foram adquiridos anteriormente pelos alunos, em outros contextos e vivências. O ato de "[...] ensinar ciências é procurar que nossos alunos e alunas se transformem, com o ensino que fazemos, em homens e mulheres mais críticos" (CHASSOT, 2011, p. 56). Assim, ao pensar no planejamento das aulas, motivamo-nos, a trabalhar a questão ambiental relacionada com os conceitos científicos de química, e ainda aos que tratam dos alimentos tentando provocar nos alunos o movimento da reflexão. 
Há um continuado desafio: o quanto nós educadores e educadoras de professoras e professores somos capazes de envolvê-los nas discussões dos problemas que lhes são mais próximos. Estes são suficientemente relevantes para se transformar nossas alunas e nossos alunos em mulheres e homens críticos, que serão os responsáveis pela construção de uma sociedade com menos desigualdades (CHASSOT, 2011, p. 140).

Por isso, a preocupação em abordar a Educação Ambiental (EA) no ensino de Química, vista a importância na formação de sujeitos críticos, que transformem a realidade do mundo em que vivemos. Pois, "o conhecimento não está só nos livros, mas na vida, nas experiências que acontecem em múltiplos outros espaços/tempos fora da escola. A educação ambiental se constitui, se organiza e se articula com outras $n$ práticas comunicacionais" (TRISTÃO, 2004, p. 69). A EA “[...] tem como pressuposto pedagógico a articulação entre 0 conhecimento sobre os processos ambientais, a intencionalidade entre os sujeitos em sua relação com a natureza e a transformação social, ou seja, a substituição radical dos modelos de sociedade que vêm destruindo o planeta" (TOZONI-REIS, 2008, p. 70-71).

Com esse cuidado planejamos as aulas de Química envolvendo a EA como prática pedagógica inovadora, vivenciada pela estagiária no estágio de docência, e também com base nas experiências e pesquisas durante a formação inicial em projetos de pesquisa sobre a temática da EA. A seguir, apresentamos o contexto em que a atividade docente foi realizada, bem como o detalhamento metodológico.

\section{Metodologia: Planejamento das Aulas}

A atividade aqui descrita foi realizada na disciplina de Estágio Curricular Supervisionado IV: Química no Ensino Médio, ofertada pelo curso de Química Licenciatura de uma Universidade Federal. O contexto da ação desenvolvida foi uma Escola Estadual de Educação Básica, em duas turmas de $1^{\circ}$ ano do Ensino Médio, com 24 e 31 alunos respectivamente. O desafio foi planejar aulas envolvendo a EA nas aulas de Química. Sendo assim, os planos de aulas elaborados para cada turma continham um questionário de reconhecimento sobre as concepções dos alunos, o qual por meio das questões visava desenvolver o pensamento crítico e reflexivo dos alunos do 
Ensino Médio, provenientes dos mais diversos contextos sociais da cidade de Cerro Largo - RS.

Quadro 1: Questionários sobre Química, Saúde e Meio Ambiente.

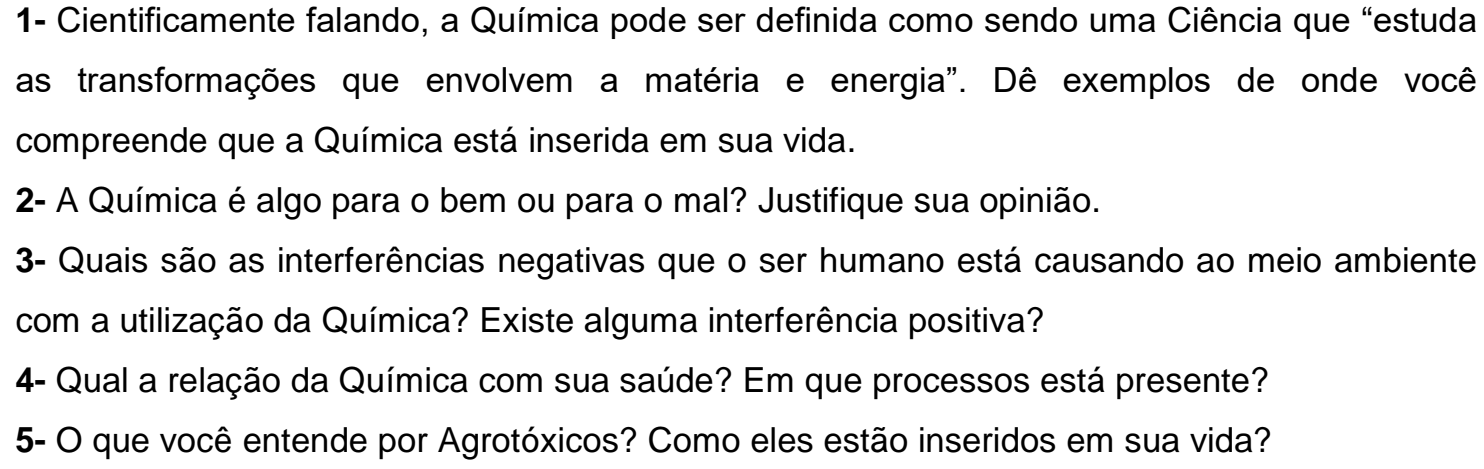

2- A Química é algo para o bem ou para o mal? Justifique sua opinião.

3- Quais são as interferências negativas que o ser humano está causando ao meio ambiente com a utilização da Química? Existe alguma interferência positiva?

4- Qual a relação da Química com sua saúde? Em que processos está presente?

5- O que você entende por Agrotóxicos? Como eles estão inseridos em sua vida?

Fonte: Elaborado pelos autores.

Dentre as atividades planejadas e realizadas no percorrer das aulas de Química, destacamos na sequência a problematização e discussão da ação docente, em atenção aos questionários dialogados com os referenciais da área

\section{Resultados e Discussão}

As perguntas elaboradas no questionário foi para envolver os alunos a pensar em possibilidades, como a Química está envolvida em seu cotidiano no dia a dia, àquilo que pode estar relacionado com o bem-estar, mas também com malefícios, ambos com inúmeros exemplos divulgados nas mídias. $\mathrm{Na}$ sequência da aula, após os alunos responderem ao questionário proposto, iniciamos a leitura e diálogo sobre uma reportagem que tratava da análise de agrotóxicos nos alimentos, para trazer ao contexto da aula de Química a relação ambiental com a nossa saúde. Assim fomos percebendo como a Química interfere no processo de produção dos alimentos e inclusive nas análises diagnósticas como a apresentada na reportagem.

$\mathrm{Na}$ primeira aula, assim como nas subsequentes, o assunto ambiental foi envolvido quando possível, desde a construção dos modelos atômicos com materiais alternativos reutilizáveis possibilitando ao aluno compreender as ideias que fundamentam a construção de cada modelo exposto em aula. $\mathrm{Ou}$ seja, as atividades relacionadas com a EA estiveram presentes no decorrer das aulas, assim como as ações de avaliação durante todo o processo de forma contínua para atender as necessidades dos alunos (UHMANN, 2017). 
Trabalhar a EA no contexto da sala de aula possibilita a formação cidadã de nossos alunos. "A cidadania que queremos é aquela que passa a ser exercida através de posturas críticas na busca de modificações do ambiente natural - e que estas sejam, evidentemente, para melhor" (CHASSOT, 2011, p. 140). Para que significativas mudanças ocorram na sociedade atual a fim de cuidar o ambiente, principalmente para as futuras gerações, precisamos de "[...] práticas cotidianas efetivas, mais flexíveis e de ações simultâneas locais/globais" (TRISTÃO, 2004, p. 25) para que todos possam desfrutar de um ambiente sustentável.

Pensando na necessidade atual, a escola precisa atuar como um pilar na construção de atitudes junto aos sujeitos preocupados e atuantes frente às questões ambientais, ao aliar o conhecimento científico com as práticas sustentáveis e cotidianas dos alunos e suas famílias. O que podemos observar em estudos recentes sobre a EA nas escolas, é que uma minoria dos professores está de fato realizando ações em prol da construção de cidadãos críticos frente à sustentabilidade do meio ambiente.

Pensando nessa questão, já na primeira aula de Química propusemos um questionário para compreender as concepções dos alunos sobre a relação da Química e dos conceitos científicos com a vida, saúde, alimentação e meio ambiente. No item que segue, elencamos as respostas dos 55 alunos que integram as duas turmas do $1^{\circ}$ ano do Ensino Médio, contexto em a ação foi realizada.

\title{
Diálogo Sobre as Concepções dos Alunos
}

Iniciamos com as ideias de Chassot (2011, p. 99):

\begin{abstract}
Ao invés de apresentarmos o conhecimento pronto, é preciso resgatar os rascunhos. Também é preciso envolver alunos e alunas em atividades que busquem ligações com seus passados próximos e remoto, através da compreensão de como se enraíza e é enraizada a construção do conhecimento e quanto isso pode ser um facilitador da preparação do futuro.
\end{abstract}

Assim, ao adentrar na sala de aula, buscamos introduzir os alunos no movimento de pensar como a Química pode estar presente em nossas vidas, qual a relação que possui com o bem-estar, assim como a reflexão acerca do 
tema ambiental pelos alunos. Num primeiro momento a sensação foi de impacto por parte dos alunos. Percebemos que não estavam acostumados com questionamentos planejados (quadro 1), muito menos a pensarem criticamente. Ao fazer o movimento da reflexão com o questionário, buscamos resgatar o que emergiu nas respostas dos alunos.

A primeira pergunta do questionário remetia ao conceito do que era a Química enquanto Ciência solicitava aos alunos exemplificassem onde compreendiam que a Química estaria inserida em suas vidas. Para esta pergunta, montamos um quadro reunindo as respostas mais comuns que apareceram visualizando quais as situações mais citadas.

Quadro 2: Respostas à pergunta no 1 do questionário do quadro 1.

\begin{tabular}{|c|c|c|}
\hline Classificação Geral & Exemplo & No de alunos \\
\hline \multirow{4}{*}{ Higiene } & Shampoo & 13 \\
\cline { 2 - 3 } & Banho & 3 \\
\cline { 2 - 3 } & Escovar os dentes & 2 \\
\cline { 2 - 3 } & Saúde & 6 \\
\hline \multirow{4}{*}{ Alimentos } & Suco & 8 \\
\cline { 2 - 3 } & Açúcar (dissolução) & 2 \\
\cline { 2 - 3 } & Preparo de comida & 8 \\
\cline { 2 - 3 } & Refrigerante & 5 \\
\cline { 2 - 3 } & Ingestão de alimentos & 8 \\
\hline \multirow{4}{*}{ Fenômenos } & Frio (gelo) & 3 \\
\cline { 2 - 3 } & Quente & 2 \\
\cline { 2 - 3 } & Gasoso (vapor) & 2 \\
\cline { 2 - 3 } & Reações & 2 \\
\cline { 2 - 3 } & Matéria & 29 \\
\cline { 2 - 3 } & Mistura homogênea e heterogênea & 2 \\
\hline Outros & Em tudo/entre outros & 2 \\
\hline
\end{tabular}

Fonte: Elaborado pelos autores.

Outros exemplos, além dos expostos no Quadro 2 citados pelos alunos e que chamaram atenção, é que a Química estaria no clima, nas roupas, nas lâmpadas, no carro, nos fenômenos de massa, volume, densidade e temperatura, na maturação das frutas, na aplicação dos agrotóxicos, na produção de pão, ao fazer café, na industrialização, nos sabões e detergentes utilizados no dia a dia. Evidenciamos diferentes opiniões acerca das relações da Química com as atividades cotidianas pelos exemplos citados. Mais da metade dos alunos (55 no total) expuseram que a Química estaria em tudo, o que é um bom fator ao considerarmos os conhecimentos prévios.

Os exemplos mais citados observando o Quadro 2 foi o shampoo referente à higiene para a categoria fenômenos que se refere aos físicos e 
químicos. Foi destaque o quente e o frio relacionado na maioria das respostas à água. A categoria alimentos foi a que mais se destacou nas respostas da questão 1, principalmente na ingestão e preparo da comida, bem como a dissolução do suco e do açúcar. Nos excertos a seguir, três concepções diferentes. A seguinte considera as transformações e composição dos objetos: "Em tudo, pois tudo possui matéria (é formado de matéria). Exemplos: alimentos, produtos de limpeza (shampoo)" (Aluno 12). Outro aluno tem conhecimento sobre as transformações da matéria, pois: "ao ingerir alimento, a matéria vira energia” (Aluno 31).

Ambos os alunos fizeram relação com a matéria, suas transformações e composição, ao qual Braibante e Zappe (2012, p. 10) afirma e expõe que; "[...] desde o início da civilização, o homem é o principal responsável pelas transformações ocorridas na natureza em razão da evolução da sua espécie e da crescente busca por espaço e alimento". Assim, conhecer a Química e como se aplica em nosso cotidiano está relacionado a muito mais que conhecer as coisas compostas e como são transformadas, mas também como e porque acontecem determinados fenômenos.

O que requer pensar sobre a relação com nossa saúde, como se dá os processos industriais, as possibilidades de manipulação do capitalismo sobre os produtos produzidos, os alimentos e o uso de agrotóxicos e transgênicos. $E$ com relação a isso, como professores de Química percebemos que a função da escola é alfabetizar cientificamente nossos alunos para que possam realizar uma leitura crítica do mundo (CHASSOT, 2011), que os permita criticar e atuar nas transformações da sociedade.

Os questionamentos (2 e 3 ) realizados sobre as implicações boas ou ruins da Química, bem como os exemplos e interferências positivas e negativas vai de encontro a esta leitura crítica do mundo, pois é necessário pensar um pouco mais sobre a relação da Química com a nossa vida. Assim apresentamos o Quadro 3 reunindo os itens principais que emergiram nas respostas dos alunos. 
ISSN - 1413-8638

E-ISSN - 2238-5533

v. 23, n.2, p. $155-166,2018$

Quadro 3: Principais apontamentos realizados pelos alunos nas questões 2 e 3.

\begin{tabular}{|l|l|}
\hline Bem & $\begin{array}{l}\text { Vacinas, cura de doenças, produção de alimentos com agrotóxicos, produção de } \\
\text { bens de consumo, tratamento da água, substâncias. }\end{array}$ \\
\hline Mal & Agrotóxicos nos alimentos, poluição, bombas atômicas. \\
\hline Positivo & $\begin{array}{l}\text { Agricultura, avanços na medicina (exames, cirurgias, remédios), agrotóxicos, } \\
\text { energias renováveis, produção de alimentos, utilização medicinal de novas } \\
\text { plantas, shampoo para queda de cabelos, tratamento do esgoto, fertilizantes na } \\
\text { agricultura. }\end{array}$ \\
\hline Negativo & $\begin{array}{l}\text { Destruição do meio ambiente, agrotóxicos (contaminação dos lençóis freáticos, } \\
\text { plantas, solo e ar; morte de animais), gases tóxicos das fábricas, experimentos } \\
\text { com animais, poluição de rios e morte dos peixes, câncer relacionado ao uso de } \\
\text { agrotóxicos, radiação, desmatamento, derramamento de petróleo no mar. }\end{array}$ \\
\hline
\end{tabular}

Fonte: Elaborado pelos autores.

Observando as respostas, percebemos que a relação com os agrotóxicos surgiu tanto positivamente quanto negativamente, se fez presente e se caracteriza como uma questão controversa a ser dialogada em sala de aula. Reis (2007, p. 127) chama atenção afirmando: "[...] controvérsias deste tipo não podem ser resolvidas simplesmente numa base técnica, pois envolvem outros aspectos, tais como hierarquizações de valores, conveniências pessoais, questões financeiras, entre outras". O exposto no quadro 3 tem relação com a saúde, alimentos e agrotóxicos, que Damo (2012, p. 29) problematiza:

[...] a adição de químicos sintéticos, a exemplo dos pesticidas e herbicidas, largamente utilizados na agricultura convencional e que permanecem residuais nos alimentos e no ambiente pode ser considerada uma severa alteração ambiental, já que influi direta ou indiretamente nas condições de saúde e, consequentemente, na qualidade da vida humana e no equilíbrio dos ecossistemas.

Assim, tais questões precisam ser discutidas em sala de aula, para que os alunos compreendam que existem os dois lados nas interferências da Química em nosso cotidiano. Dessa forma: “[...] ao educador cabe comprometer-se com o projeto de uma Educação Ambiental Problematizadora e com a formação de sujeitos críticos, nos quais reconhecemos a capacidade de compreender a realidade agindo conforme o contexto do problema" (DAMO, 2012, p. 34). Salientamos que todas as questões, depois de respondidas foram discutidas em sala de aula, presentes no quadro 3 são de extrema importância na discussão no sentido de ampliar a visão dos alunos acerca dos exemplos citados e das controvérsias envolvidas, já que muitos alunos também responderam nas questões que não sabiam aspectos positivos e/ou negativos. Assim também para o bem e/ou mal, ou ainda citaram apenas para um deles. 
$\mathrm{Na}$ questão 4, a relação com a saúde apareceu principalmente na relação com a medicina, nos medicamentos, vacinas, tratamento de doenças, equipamentos, produtos de higiene, sendo que as relações foram feitas apontando principalmente aspectos positivos da Química na saúde. A intenção principal desta pergunta quando foi elaborada, era observar se os alunos relacionariam o consumo de alimentos com a relação saúde e Química, em preocupação ao seguinte:

[...] muitas vezes os setores produtivos no Modo de Produção Capitalista não colocam em primeiro plano a qualidade dos alimentos produzidos, mas preocupam-se apenas com produtividade e lucratividade, desrespeitando o direito das pessoas a consumir alimentos livres de substâncias prejudiciais à saúde (DAMO, 2012, p. 16).

Foi surpreendente que grande parte dos alunos, fez sim relação da saúde com os alimentos ingeridos diariamente. Sendo importante para nós, principalmente pelo contexto social dos alunos, ou seja, das turmas em que aconteceu o estágio, onde muitos residem no meio rural e/ou tem contato com o mesmo por meio de familiares.

Conscientizar sobre as implicações da utilização dos agrotóxicos e sua relação com conceitos de química ensinados na escola é muito importante, principalmente para aqueles estudantes de regiões agrícolas, que convivem diariamente com esse tipo de produto, proporcionando a aproximação do ensino de química com a realidade que os cerca (BRAIBANTE; ZAPPE, 2012, p. 15).

Por isso a importância de que "a escola precisa marcar o desejo pelo saber na relação entre os sujeitos aprendentes/ensinantes na constituição de pertencimento do conhecimento, através do diálogo reflexivo e argumentativo no coletivo" (UHMANN, 2013, p. 28). Pensando na construção de conhecimento que possibilite ao aluno se constituir como um cidadão crítico e atuante, que emergiu a questão 5 do questionário, onde os alunos foram desafiados a definir o que eram os agrotóxicos com base em seus conhecimentos prévios apontando na relação principalmente com a alimentação.

Muitos alunos não elaboraram uma definição ao termo agrotóxico, por isso, esse foi um dos pontos mais debatidos em sala de aula, bem como a ampla variedade existente desses produtos. O que mais apareceu nas 
respostas foi que os agrotóxicos são utilizados na agricultura para produção de alimentos, controle de pragas, e assim vão causando alguns efeitos nocivos ao ambiente e a saúde pela ingestão de alimentos contaminados. O termo veneno apareceu com frequência nas respostas abordadas junto com a definição de agrotóxicos, pois estão envolvidos na definição de variados tipos de produtos, desde praguicidas até os produtos que compramos em supermercados que utilizamos em nossas casas para afugentar os insetos indesejados.

Ao ampliarmos a discussão em sala de aula, trouxemos a questão da produção orgânica como opção em pequena escala, o que poderia ser mais discutido em termos de sustentabilidade. O termo sustentável "[...] pressupõe um equilíbrio do ser humano com ele mesmo, com o planeta e com o universo" (SANTOS, 2006, p. 29), mesmo sabendo da dificuldade de uma produção em larga escala para suprir a demanda mundial de alimentos. No entanto, precisamos nos informar, conhecer e estudar mais sobre os pontos positivos e negativos de tal produção, além do mais, também saber que na produção em pequena escala os preços são mais elevados do que na produção de larga escala. Porém, precisamos aderir aos produtos das feiras adquirindo temperos, verduras, hortaliças entre outros. Com o questionário foi possível discutir aspectos diretamente interligados às nossas vidas.

\footnotetext{
O papel da escola é construir valores e estratégias que possibilitem aos/às estudantes determinarem o que é melhor conservar em sua herança cultural, natural e econômica para se alcançar um nível de sustentabilidade na comunidade local que contribui, ao mesmo tempo, com os objetivos em escalas nacional e global (TRISTÃO, 20, p. 66).
}

Portanto, considerando a importância de tornarmos o local onde vivemos em um ambiente ecologicamente mais equilibrado, se faz necessária que as práticas de EA estejam presentes nas nossas aulas num contínuo repensar e refazer das ações docentes com função cultural, social e ambiental.

\section{Considerações Finais}

O ato de adentrar a sala de aula e ser responsável por mediar o conhecimento é extremamente complexo. Trazer para a aula a metodologia de relacionar os conceitos de Química e a questão da EA pode dar a sensação de entusiasmo e ao mesmo tempo de frustação. Ser professor é isso, é ter a 
sensação de andar em uma montanha russa todos os dias, pois estar a todo o momento pensando e organizando a aula, a atividade, a prática, o experimento tem esse diferencial de desacomodação e organização.

Iniciativas de abordagens sobre a temática ambiental, apresentadas ao trabalho docente se faz emergente no atual contexto social. É necessário estabelecer relações urgentes entre os conceitos científicos de todas as áreas, em especial de Ciências e Química para que os alunos encontrem sentido e significado nos conceitos em seu cotidiano e possam realizar a leitura do mundo em que vivem, transformando-o para melhor. Chassot (2011) destaca sobre a necessidade de alfabetizarmos cientificamente nossos alunos. Nesse viés, é intrínseco estabelecer relações entre a Química e a $E A$, visto a interferência desta Ciência na nossa saúde por meio de diferentes contextos, como a alimentação, o habitat e a produção de bens de consumo.

Portanto, urge envolver os alunos na aula ao instigá-los a pensar e escrever levando em consideração os conhecimentos prévios e a capacidade de criatividade e responsabilidade, resgatando os saberes já construídos, desenvolvendo a habilidade do pensamento crítico, habilitando espaços de expressão das opiniões e reflexões. Enfim, o estágio de docência, bem como este estudo, oportunizou contribuições no processo construtivo já na formação inicial, compreendendo que a prática docente é um contínuo olhar para a mesma de forma crítica e reflexiva em atenção às questões da atualidade, como da EA.

\section{Referências}

BRAIBANTE, Mara Elisa Fortes; ZAPPE, Janessa Aline. A Química dos Agrotóxicos. Revista Química Nova na Escola, v. 34, n. 1, p. 10-15, fev., 2012. Disponível em: < http://qnesc.sbq.org.br/online/qnesc34 1/03-QS-0211.pdf >. Acesso em 15 fev. 2018.

CHASSOT, Attico. Alfabetização Científica: questões e desafios para a educação. ljuí: Unijuí: 2011.

CHASSOT, Attico. Sobre Prováveis Modelos Atômicos. Revista Química Nova na Escola, n. 3, p. 1, mai. 1996. Disponível em: < http://qnesc.sbq.org.br/online/qnesc03/ensino.pdf >. Acesso em 19 jun. 2018.

DAMO, Andreisa. Educação Ambiental, Qualidade Alimentar e Saúde: Estudo de Caso das Representações Sociais dos Consumidores da Feira 
Ecológica da FURG. Dissertação (Mestrado), Universidade Federal do Rio Grande, Mestrado em Educação Ambiental, Rio Grande, 2012.

DELIZOICOV, Demétrio; ANGOTTI, José André; PERNAMBUCO, Marta Maria. Ensino de Ciências: Fundamentos e Métodos. São Paulo: Cortez, 2003.

REIS, Pedro Rocha dos. Os Temas Controversos na Educação Ambiental. Pesquisa em Educação Ambiental, vol. 2, n. 1, 2007, p. 125-140. Disponível em: < https://www.revistas.usp.br/pea/article/view/30021/31908 >. Acesso em: 20 jun. 2018.

SANTOS, Maria Glória de Faria Nunes. Educação Ambiental no Livro Didático: Análise dos Manuais da 4⿳亠丷厂 Série do Ensino Fundamental Adotados nas Escolas Públicas Brasileiras. 241f. Dissertação (Mestrado), Universidade Lusófona de Humanidades e Tecnologias, Departamento de Ciências Sociais e Humanas, Área de Ciências da Educação, Lisboa, Portugual, 2006. Disponível em:

http://www.cchla.ufrn.br/geoesp/arquivos/artigos/ArtigoEducacaoAmbientanosLi vrosDidaticos.pdf >. Acesso em: 10 jun. 2018.

TOZONI-REIS, Marília Freitas de Campos. Educação Ambiental: natureza, razão e história. 2ed. Campinas, São Paulo: Autores Associados, 2008.

TRISTÃO, Marta. A Educação Ambiental na Formação de Professores: redes de saberes. São Paulo: Annablume, 2004.

UHMANN, Rosangela Inês Matos. O Professor em Formação no Processo de Ensinar e Aprender ao Avaliar. Curitiba: Appris. 2017. 